\title{
Uncertainties And Governance Structure In Incentives Provision For Product Quality
}

\author{
Wendong Deng and George Hendrikse
}

(forthcoming in Ehrmann, T. et al.,

Governance of Alliances, Cooperatives and Franchise Chains, Springer, 2012)

\begin{tabular}{|l|l|}
\hline \multicolumn{2}{|l|}{ ERIM REPORT SERIES RESEARCH IN MANAGEMENT } \\
\hline ERIM Report Series reference number & ERS-2012-016-ORG \\
\hline Publication & August 2012 \\
\hline Number of pages & 23 \\
\hline Persistent paper URL & http://hdl.handle.net/1765/37346 \\
\hline Email address corresponding author & wdeng@rsm.nl \\
\hline Address & Erasmus Research Institute of Management (ERIM) \\
& RSM Erasmus University / Erasmus School of Economics \\
& Erasmus Universiteit Rotterdam \\
& P.O.Box 1738 \\
& 3000 DR Rotterdam, The Netherlands \\
& Phone: + 31 10 408 1182 \\
& Fax: $\quad+31104089640$ \\
& Email: info@erim.eur.nl \\
& Internet: $\quad$ www.erim.eur.nl \\
\hline
\end{tabular}

Bibliographic data and classifications of all the ERIM reports are also available on the ERIM website: www.erim.eur.nl 


\section{ERASMUS RESEARCH INSTITUTE OF MANAGEMENT}

\section{REPORT SERIES}

\section{RESEARCH IN MANAGEMENT}

\begin{tabular}{|l|l|}
\hline \multicolumn{2}{|l|}{ ABSTRACT AND KEYWORDS } \\
\hline Abstract & $\begin{array}{l}\text { This paper compares the product quality provision of cooperatives and investor owned firms } \\
\text { (IOFs) by highlighting the impacts of uncertainties in agricultural production and marketing, and } \\
\text { farmers' risk aversion. In a principal-agent model, we show that the linear contract can shift the } \\
\text { risk of market uncertainty from farmers to processors, and pooling can share the risk of } \\
\text { production uncertainty among cooperative members. Complete pooling places the cooperative at } \\
\text { a disadvantage relative to the IOF in a quality-differentiated market due to the loss of free-riding } \\
\text { dominating the gain of risk-sharing. Product quality of cooperatives decreases when the } \\
\text { membership size increases. Cooperatives can overcome this disadvantage by partial pooling. } \\
\text { Product quality of cooperatives will be equivalent to that of IOFs when an optimal income rights } \\
\text { structure with partial pooling is adopted. }\end{array}$ \\
\hline Free Keywords & quality, cooperative, investor owned firm, pooling \\
\hline Availability & $\begin{array}{l}\text { The ERIM Report Series is distributed through the following platforms: } \\
\text { Academic Repository at Erasmus University (DEAR), DEAR ERIM Series Portal } \\
\text { Social Science Research Network (SSRN), SSRN ERIM Series Webpage } \\
\text { Research Papers in Economics (REPEC), REPEC ERIM Series Webpage }\end{array}$ \\
\hline Classifications & $\begin{array}{l}\text { The electronic versions of the papers in the ERIM report Series contain bibliographic metadata } \\
\text { by the following classification systems: } \\
\text { Library of Congress Classification, (LCC) LCC Webpage } \\
\text { Journal of Economic Literature, (JEL), JEL Webpage } \\
\text { ACM Computing Classification System CCS Webpage } \\
\text { Inspec Classification scheme (ICS), LCS Webpage }\end{array}$ \\
\hline
\end{tabular}




\title{
Uncertainties and Governance Structure in Incentives Provision for Product Quality
}

\author{
Wendong Deng \\ George Hendrikse ${ }^{1}$
}

\begin{abstract}
This paper compares the product quality provision of cooperatives and investor owned firms (IOFs) by highlighting the impacts of uncertainties in agricultural production and marketing, and farmers' risk aversion. In a principal-agent model, we show that the linear contract can shift the risk of market uncertainty from farmers to processors, and pooling can share the risk of production uncertainty among cooperative members. Complete pooling places the cooperative at a disadvantage relative to the IOF in a quality-differentiated market due to the loss of free-riding dominating the gain of risk-sharing. Product quality of cooperatives decreases when the membership size increases. Cooperatives can overcome this disadvantage by partial pooling. Product quality of cooperatives will be equivalent to that of IOFs when an optimal income rights structure with partial pooling is adopted.
\end{abstract}

Keywords: Quality, Cooperative, Investor Owned Firm, Pooling

\footnotetext{
${ }^{1}$ Rotterdam School of Management, Erasmus University, wdeng@rsm.nl and ghendrikse@rsm.nl
} 


\section{Introduction}

In the organizational economics literature, cooperatives are commonly considered as less efficient in terms of delivering high-quality products to the market. Saitone and Sexton(2009, p1224) list a number of disadvantages of cooperatives in the provision of product quality, including: "(i) revenue pooling, which in quality-differentiated markets is generally regarded as disadvantageous due to the potential for adverse selection; (ii) patronage-based financing, which leads to the horizon problem and underinvestment in long-term strategies that can enhance objective or perceived product quality; (iii) providing a 'home' for member production, which is problematic both with respect to product quality and the potential to glut niche markets; (iv) difficulties in terminating 'marginal' members; and (v) limitations on procuring product from nonmember sources." These considerations have led to the pessimistic prospect of cooperatives' future regarding their ability to compete and survive in the modern agricultural markets (Fulton, 1995; Cook, 1995).

However, nowadays there are many large cooperatives active in the market, competing with IOFs for market share by delivering products with superior quality. For example, in the Brazilian broiler industry, Cechin et al. (2012) find that suppliers delivering to a cooperative are performing better in terms of quality than suppliers delivering to an IOF. Another empirical observation raising doubts about the prospects for cooperatives is that in many sectors they coexist with investor owned firms (IOFs). Mérel et al. (2009) posit that several particular characteristics of cooperatives, such as the preference of consumers for cooperative products, better communication, insurance function of pooling, and etc., have the potential to counterbalance the disadvantages of cooperatives in the provision of product quality. Other cooperative researchers consider the components of social capital in cooperatives, such as identification and trust, as cooperatives' comparative advantage in the competition with IOFs (Uzea and Fulton, 2009; Feng et al., 2011).

This paper formulates a principal-agent model regarding the provision of product quality by different governance structures, including self-processing, cooperative and IOF. The impacts on product quality of three aspects are highlighted: farmers' risk-aversion, uncertainties, and (partial) pooling. First, although farmers are usually regarded as risk-averse (Staatz, 1987), in most of the conceptual models analyzing the decision-making of farmers, their characteristic of risk aversion is not explicitly captured. Second, agricultural production and marketing are subject to different types of risks, including biological risk, price risk and institutional risk (Bogetoft and Olesen, 2004). We highlight two types of risk in agribusiness: the risk of market uncertainty and production uncertainty (Knoeber and Thurman, 1995). Third, a pooling policy is often adopted by cooperatives (Hendrikse, 2011). We show that a cooperative with a complete pooling policy will have lower product quality than an IOF. The growth of the cooperative membership will hamper the cooperative's provision of product quality. Cooperative researchers have pointed out that large cooperatives have to adopt the strong incentive structure by paying a "quality-specific price" to the members with high product quality (Hendrikse, 2011). We investigate how a large cooperative can maintain an optimal product quality level by designing an optimal income rights structure with partial pooling. Partial pooling is effective because it provides on the one hand insurance to risk-averse farmers and on the other hand incentive for quality.

The remainder of this paper is organized as follows. In Section 2, we formulate the model. Section 3 compares the quality provision of different governance structures. In Section 4, we investigate the 
design of a cooperative's income rights structure, and determine the optimal quality provision for large cooperatives. Section 5 discusses the findings and the last Section concludes.

\section{Model}

This section develops a non-cooperative game with the upstream farmers and a downstream processor. Assume that there are $N$ identical farmers in a region producing a certain raw commodity that needs to be processed before reaching the final market. The farmers each produce only one unit of the raw produce and individually make the decisions regarding the quality of their produce. The cost related to the product quality provision of farmer $i$, where $i=1,2, \ldots, N$, is:

$$
C\left(q_{i}\right)=\frac{1}{2} c q_{i}^{2}
$$

The quality provision cost coefficient $c$ is identical for all farmers and is treated as a constant. Without loss of generality, the production costs of the raw produce, and the processing costs and valued-added of the final product are sunk and will not enter into the analysis. We also assume that one unit of the raw produce will be processed into one unit of the final product. We refer to the difference in the quality as in the realm of vertical product differentiation (Mérel et al., 2009). The quality of the raw produce determines the quality of the final product, and the processing itself cannot change the product quality.

The farmers are risk-averse, their von Neumann-Morgenstern utility function of an uncertain economic payoff $\pi_{i}(i=1,2, \ldots, N)$ is:

$$
U_{i}=-\exp \left(-r \pi_{i}\right)
$$

Parameter $r$, which is assumed to be identical for all farmers, is the farmers' coefficient of absolute risk aversion, i.e., the higher $r$ is, the more risk averse the farmers are.

We highlight two types of risk in our model. The first type of risk is from the market uncertainty. Because we want to investigate the provision of product quality, in current model we only try to capture the uncertainty in the market's preference of product quality. Assuming that the market is competitive and quality-differentiated, the final product's unit price in the market is linearly increasing with the product quality, nevertheless, with a certain level of uncertainty:

$$
P_{m}=\left(b+\epsilon_{1}\right) q
$$

$q(>0)$ denotes the quality of the final product sold, which is determined by the quality of the raw produce, and the coefficient $b(>0)$ denotes the marginal market price with respect to the product quality. $b$ can also be understood as the market's aggregate "taste parameter" in the model of Mussa and Rosen (1978). The utility that the market derives from consuming one unit of the product with the quality of $q$ is $b q$, and it pays the equivalent price $b q$ to the product seller. The market prefers higher ranked quality by paying a higher price as $b>0$. However, the preference or taste of the market is uncertain. Therefore, there is a normally distributed random noise term $\epsilon_{1}$ in the marginal market price, with mean zero and variance $\sigma_{1}^{2}$.

The second type of risk is from the uncertainty in agricultural production per se. Assuming that farmer $i$ 's planned quality for his production is $q_{i}$. However, the farmer's realized product quality 
after harvest is $q_{i}+\epsilon_{2 i}$, where $\epsilon_{2 i}$ is a normally distributed random noise term, with mean zero and variance $\sigma_{2 i}^{2}$, representing the uncertainty in his production. We assume that production uncertainty is common for all farmers, i.e., $\epsilon_{2 i}=\epsilon_{2}, \sigma_{2 i}^{2}=\sigma_{2}^{2}$. The variances $\sigma_{1}^{2}$ and $\sigma_{2}^{2}$ represent the objective risk of the market and production, respectively.

Three governance structures regarding the processing of a farmer's produce will be considered: selfprocessing, cooperative and IOF. In the following, we will analyze how the risk of market and production uncertainty affects the farmers' utility when they trade with different processors, and the consequence on the provision of product quality.

\section{Self-processing}

Consider the situation where a farmer processes the raw produce into the final product by himself, and then sells the final product in the market directly. In self-processing, a farmer, also as the processor, sells the product in the market and will receive the price $P_{m}$ from the market according to his product quality $q_{i}$. There is indeed no contract between the farmer and processor. Farmer $i^{\prime} \mathrm{s}$ economic payoff is:

$$
\pi_{i}=\left(b+\epsilon_{1}\right)\left(q_{i}+\epsilon_{2}\right)-\frac{1}{2} c q_{i}^{2} .
$$

The farmer's utility function is:

$$
U_{i}=-\exp \left\{-r\left[\left(b+\epsilon_{1}\right)\left(q_{i}+\epsilon_{2}\right)-\frac{1}{2} c q_{i}^{2}\right]\right\}
$$

The farmer's certainty equivalent payoff is:

$$
C E_{i}=b q_{i}-\frac{1}{2} c q_{i}^{2}-\frac{1}{2} k_{1} q_{i}^{2}-\frac{1}{2} k_{2} b^{2}+C E\left(\epsilon_{1} \epsilon_{2}\right)
$$

$k_{1}=r \sigma_{1}^{2}, k_{2}=r \sigma_{2}^{2}$ denote the farmer's subjective risk toward the market and production uncertainty, respectively. Each term of subjective risk is the corresponding objective risk scaled by the farmer's degree of aversion (see Bolton and Dewatripont, 2005, Chapter 4). The term $\frac{1}{2} k_{1} q_{i}^{2}$ and $\frac{1}{2} k_{2} b^{2}$ are risk premiums, which are the disutility of risk. $C E\left(\epsilon_{1} \epsilon_{2}\right)$ is the risk premium of the joint contribution of the market and production uncertainty. It is negative and decreases when the market and production uncertainty increases.

The farmers can also sell the raw produce to an enterprise processor. The enterprise processor has one of the two governance structures: an open-membership cooperative or an IOF. We model the transactions between the enterprise processor and the farmers in a principal-agent framework (Holmström, 1979). The processor acts as a principal, and the farmers are agents who are rewarded by the outcome of their efforts invested in the product quality. The efforts per se are not observable, but the quality $q$ of the delivered raw produce from the farmers to the processor is contractible. The processor offers the farmers a linear contract stating the payment formula as:

$$
P=\alpha+\beta q
$$


$P$ is the unit price of the raw produce that the processor will pay for. $\alpha(\geq 0)$ is the base (guarantee) price and $\beta(\geq 0)$ is the incentive regarding the product quality or the quality premium. An important function of the linear contract between the principal and agent is to balance the costs of risk bearing against the incentive gains (Holmström, 1979). This form of contract is commonly used in agribusiness, whether the processor is an IOF or a cooperative (Gow et al., 2000; Cechin et al, 2012).

\section{Cooperative}

Confronted with the market and production uncertainty, the individual farmers who used to process individually and trade directly in the market may have the incentive to form a marketing cooperative with an open-membership policy. The members of the cooperative jointly own the processor, but the farmers remain independent regarding their quality decisions. We assume that the cooperative adopts the traditional principle of complete pooling policy. This assumption will be relaxed later. The marketing contract between the cooperative and the members has the payment formula as follows:

$$
\begin{gathered}
P_{c}=\alpha_{c}+\beta_{c} Q_{c} . \\
Q_{c}=\frac{1}{n} \sum_{i}^{n}\left(q_{i}+\epsilon_{2 i}\right) .
\end{gathered}
$$

The price consists of a fixed base price $\alpha_{c}$ and a quality-incentive $\beta_{c}$. In complete pooling, the cooperative enacts a single pool for all products with various qualities, and the members share equitably on a per-unit basis in the revenue stream that has been created (Cook and lliopoulos, 1999; Saitone and Sexton, 2009). This equality principle distributes the net revenue to members based on the delivered volume, regardless the quality of the product. Therefore, in the payment formula of the marketing contract, the quality incentive is related to the pooled or aggregate quality $Q_{c}$ instead of the individual product quality $q_{i}$, since the cooperative will also receive revenues from the market based on $Q_{c}$. A member $i$ 's economic payoff is:

$$
\pi_{i}=\alpha_{c}+\beta_{c} Q_{c}-\frac{1}{2} c q_{i}^{2}
$$

And the member's utility function is:

$$
U_{i}=-\exp \left\{-r\left[\alpha_{c}+\frac{\beta_{c}}{n} \sum_{i}^{n}\left(q_{i}+\epsilon_{2 i}\right)-\frac{1}{2} c q_{i}^{2}\right]\right\} .
$$

Different from the utility function of the self-processing farmers who trade directly in the market, the subjective risk toward market uncertainty $k_{1}$ is not in the member's utility function. This is because the members are not selling their products to the final market directly. Instead, they sell to the market via the cooperative they own and they are insulated from the market uncertainty $\epsilon_{1}$ and risk $\sigma_{1}^{2}$. Their projected income is then decided by the payment formula $P_{c}$. A member's certainty equivalent payoff is:

$$
C E_{i}=\alpha_{c}+\frac{\beta_{c}\left(q_{i}+Q_{-i}\right)}{n}-\frac{1}{2} c q_{i}^{2}-\frac{1}{2} k_{2} \frac{\beta_{c}^{2}}{n}
$$


Notice that $Q_{-i}$ is the sum of the quality decisions of the other members besides member $i$ and $\sum_{i}^{n} \epsilon_{2 i}$ has a normal distribution with variance $n \sigma_{2}^{2}$. We can see that complete pooling reduces the member's risk premium term $\frac{1}{2} k_{2} \frac{\beta_{c}^{2}}{n}$ related to the production uncertainty by a factor of $\frac{1}{n}$. It captures the risk sharing function of pooling.

IOF

An IOF procures the raw produce of the farmers and sells the processed products in the same final market. The contract the IOF offers to the farmers is:

$$
P_{f}=\alpha_{f}+\beta_{f} q_{i}
$$

Similarly, the price consists of a fixed base price $\alpha_{f}$ and an individualized quality-incentive $\beta_{f}$, and with this contract the farmers are not faced with the market uncertainty $\epsilon_{1}$ and risk $\sigma_{1}^{2}$ directly. Differently, the quality incentive is now based on the individual instead of pooled product quality. The economic payoff of a farmer $i$, who trades with the IOF, is:

$$
\pi_{i}=\alpha_{f}+\beta_{f} q_{i}-\frac{1}{2} c q_{i}^{2}
$$

His utility function is:

$$
U_{i}=-\exp \left\{-r\left[\alpha_{f}+\beta_{f}\left(q_{i}+\epsilon_{2 i}\right)-\frac{1}{2} c q_{i}^{2}\right]\right\}
$$

And, his certainty equivalent payoff is:

$$
C E_{i}=\alpha_{f}+\beta_{f} q_{i}-\frac{1}{2} c q_{i}^{2}-\frac{1}{2} k_{2} \beta_{f}^{2} .
$$

Different from the certainty payoff of the cooperative members, in farmer $i$ 's certainty equivalent payoff, both the quality incentive and risk premium of the production uncertainty are individualized.

Table 1 lists the players' decisions in three different governance structures.

\begin{tabular}{|c|c|c|c|}
\hline & Self-processing & IOF & Cooperative \\
\hline Processor & - & $\alpha_{f}, \beta_{f}$ & $\alpha_{c}, \beta_{c}$ \\
\hline $\begin{array}{c}\text { Farmer } \boldsymbol{i} \\
(\boldsymbol{i}=\mathbf{1}, \mathbf{2}, \ldots, \boldsymbol{N})\end{array}$ & $q_{i}$ & $q_{i}$ & $q_{i}$ \\
\hline
\end{tabular}

Table 1: Decisions of the farmers and the processor

Assume that the farmers' coefficient of absolute risk aversion, quality provision cost coefficient, production uncertainty, and the market's preference and uncertainty are common knowledge. The product quality is perfectly measurable. The timing of the two-stage game is as follows: (i) the principal (processor) chooses the $\alpha$ and $\beta$ of the payment formula; (ii) the agents (farmers) choose the product quality to maximize their certainty equivalent payoff. This game will be solved by backward deduction.

\section{Equilibrium}


In this section, we derive the equilibrium product quality in different governance structures and compare the farmers' certainty equivalent payoff.

\section{Self-processing}

The self-processing farmer's decision regarding product quality is obtained by the FOC of his certainty equivalent payoff:

$$
\begin{gathered}
\frac{\partial C E_{i}}{\partial q_{i}}=b-k_{1} q_{i}-c q_{i}=0 . \\
q_{i}^{*}=\frac{b}{c+k_{1}} .
\end{gathered}
$$

The result entails that if the farmer trades directly in the market, the quality of the product is determined by his subjective risk toward the market uncertainty $k_{1}$. The product quality will be reduced if the farmer's subjective risk toward the market uncertainty is high. The production uncertainty doesn't play a role in the quality decision because it is intrinsic and the farmer cannot change the disutility from the production uncertainty by choosing his product quality. However, it determines whether the farmer will participate in the market. The farmer's certainty equivalent payoff is:

$$
C E_{i}^{*}=\frac{b^{2}}{2}\left(\frac{1}{c+k_{1}}-k_{2}\right)+C E\left(\epsilon_{1} \epsilon_{2}\right)
$$

Assuming that the farmer's reservation certainty payoff is zero, when their subjective risk toward the market uncertainty $k_{1}$ and product measurement uncertainty $k_{2}$ is so large that $C E_{i}^{*}<0$, the farmer are not willing to participate in the market.

\section{Cooperative}

The cooperative members make their decisions individually. Member $i$ 's decision on his product quality is obtained by the FOC of his certainty equivalent payoff:

$$
\begin{gathered}
\frac{\partial C E_{i}}{\partial q_{i}}=\frac{\beta_{c}}{n}-c q_{i}=0 . \\
q_{i}^{*}=\frac{\beta_{c}}{n c} .
\end{gathered}
$$

While the subjective risk toward market uncertainty $k_{1}$ doesn't play a role in members' decisions now, the cooperative's membership size $n$ and quality incentive $\beta_{c}$ jointly determine the member's decision regarding product quality. As the cooperative becomes large in terms of $n$, while the arrangement of complete pooling attenuates the production risk of individual members by risk sharing, it also causes an offsetting impact - the members will free ride on other members' efforts in product quality improvement. The members have little incentive to supply high-quality product, since each member's share is relatively insensitive to his effort level in a large organization. When any individual effort will not be directly rewarded, it gives rise to free riding. Because all members are identical, the cooperative's aggregate product quality is: 


$$
Q_{c}^{*}=\frac{\beta_{c}}{n c}+\frac{1}{n} \sum_{i}^{n} \epsilon_{2 i}
$$

For the members, the risk of market uncertainty is now placed on the cooperative processor. In fact, this risk cannot be completely shifted from the members to the processor because the members are also the decision makers and residual claimants of the processor. They are actually the same people. Therefore, farmer cooperatives are usually regarded as risk averse in decision making (Staatz, 1987; Vitaliano, 1983). However, the risk-sharing is still possible between the members and processor because the equity in the cooperative can be used as a buffer to absorb temporary fluctuations in profits (Bogetoft and Olesen, 2004). In current model, we assume that the cooperative can execute this buffering function and treat the cooperative processor as risk-neutral regarding the decision of the payment formula. Assuming that the processing costs and valued-added of the cooperative processor is sunk, the processor retains no earnings and its objective is to maximize the joint certainty equivalent payoff of the processor and members, which is:

$$
\pi_{c}=E\left[n b Q_{c}^{*}-\frac{n}{2} c q_{i}^{* 2}-\frac{n}{2} k_{2} \frac{\beta_{c}^{2}}{n}\right]=n\left(\frac{b \beta_{c}}{c n}-\frac{1}{2} \frac{\beta_{c}^{2}}{c n^{2}}-\frac{1}{2} k_{2} \frac{\beta_{c}^{2}}{n}\right) .
$$

Following the FOC regarding $\beta_{c}\left(0 \leq \beta_{c} \leq b\right)$ :

$$
\begin{gathered}
\frac{\partial \pi_{c}}{\partial \beta_{c}}=\frac{b}{c n}-\frac{\beta_{c}}{c n^{2}}-\frac{k_{2} \beta_{c}}{n}=0 . \\
\beta_{c}^{*}=\frac{b}{\frac{1}{n}+c k_{2}} .
\end{gathered}
$$

It entails that the cooperative's quality incentive payment $\beta_{c}^{*}$ should increase with membership size but decrease with the members' subjective risk toward production uncertainty. The cooperative's expected aggregate product quality is:

$$
Q_{c}=E\left[\frac{\beta_{c}^{*}}{n c}+\frac{1}{n} \sum_{i}^{n} \epsilon_{2 i}\right]=\frac{b}{c\left(k_{2} n c+1\right)} .
$$

The member's certainty equivalent payoff is:

$$
C E_{i}^{*}=\frac{b^{2}}{2 c\left(k_{2} n c+1\right)}
$$

The result shows that, in comparison with self-processing and trading directly in the market, the members of the cooperative with a complete pooling policy can always obtain a positive certainty equity payoff because the cooperative processor bears the risk of market uncertainty for its members. However, the cooperative's aggregate product quality and members' certainty equivalent payoff decreases when its membership size increases, due to the increasing free-riding problem.

IOF

The farmer trading with the IOF makes the decision of the product quality based on the FOC of his certainty equivalent payoff: 


$$
\begin{gathered}
\frac{\partial C E_{i}}{\partial q_{i}}=\beta_{f}-c q_{i}=0 . \\
q_{i}^{*}=\frac{\beta_{f}}{c} .
\end{gathered}
$$

Owned by investors who can hold diversified portfolios, the IOF is modeled as risk-neutral. Assuming that the processing costs and valued-added of the IOF processor is sunk, it will maximize its total economic payoff subject to the farmers' participation constraint. The farmer's reservation certainty equivalent payoff $R$ is assumed to be equal to the certainty equivalent payoff of the cooperative members:

$$
R=\frac{b^{2}}{2 c\left(k_{2} n c+1\right)}
$$

The participation constraint of the farmers to deliver his raw produce to the IOF is:

$$
C E_{i}^{*}=\alpha_{f}+\beta_{f} q_{i}^{*}-\frac{1}{2} c q_{i}^{* 2}-\frac{1}{2} k_{2} \beta_{i}^{2} \geq R
$$

The IOF will simply pay the lowest possible fixed payment so that the farmers are just willing to deliver:

$$
\alpha_{f}^{*}=R-\frac{\beta_{f}^{2}}{2 c}+\frac{1}{2} k_{2} \beta_{f}^{2}
$$

The total expected payoff of the IOF is:

$$
\pi_{f}=E\left[n b q_{i}^{*}-n\left(\alpha_{f}^{*}+\beta_{f} q_{i}\right)\right]=n\left[\frac{b \beta_{f}}{c}-\frac{1}{2} k_{2} \beta_{f}^{2}-\frac{\beta_{f}^{2}}{2 c}-R\right] .
$$

The IOF maximizes its payoff by choosing $\beta_{f}\left(0 \leq \beta_{f} \leq b\right)$ :

$$
\begin{gathered}
\frac{\partial \pi_{f}}{\partial \beta_{f}}=n\left[\frac{b}{c}-k_{2} \beta_{f}-\frac{\beta_{f}}{c}\right]=0 . \\
\beta_{f}^{*}=\frac{b}{1+c k_{2}} .
\end{gathered}
$$

Given the contract offered by the IOF, the farmer's decision on the product quality can be obtained. As all farmers are identical, and assuming that there are $m$ farmers supplying the IOF, the expected aggregate product quality of the IOF is:

$$
Q_{f}=E\left[\frac{\beta_{f}^{*}}{c}+\frac{1}{m} \sum_{i}^{m} \epsilon_{2 i}\right]=\frac{b}{c\left(1+c k_{2}\right)} .
$$

From the equation above we see that the farmers' subjective risk toward production uncertainty $k_{2}$ determines the IOF's product quality. The farmers' certainty equivalent payoff is equal to his reservation certainty payoff and the IOF keeps the remaining part of the certainty payoff for each 
unit of the product. The IOF exists because by offering the contracts to the non-member farmers, it also insures them from the market uncertainty and elicits supply.

Comparison

Table 2 presents the comparison of the product quality, farmers' certainty equivalent payoff and the processor's payoff per unit of product in different governance structures:

\begin{tabular}{|l|c|c|c|}
\hline & Self-processing & IOF & Cooperative \\
\hline $\begin{array}{l}\text { Product } \\
\text { Quality }\end{array}$ & $\frac{b}{c+k_{1}}$ & $\frac{b}{c\left(1+c k_{2}\right)}$ & $\frac{b}{c\left(1+n k_{2} c\right)}$ \\
\hline $\begin{array}{l}\text { Farmers' } \\
\text { CE Payoff }\end{array}$ & $\frac{b^{2}}{2}\left(\frac{1}{c+k_{1}}-k_{2}\right)+C E\left(\epsilon_{1} \epsilon_{2}\right)$ & $\frac{b^{2}}{2 c\left(1+n k_{2} c\right)}$ & $\frac{b^{2}}{2 c\left(1+n k_{2} c\right)}$ \\
\hline $\begin{array}{l}\text { Processor's } \\
\text { payoff }\end{array}$ & n.a. & $\frac{b^{2}}{2 c\left(1+c k_{2}\right)}-\frac{b^{2}}{2 c\left(1+n k_{2} c\right)}$ & 0 \\
\hline
\end{tabular}

Table 2: Product quality and certainty payoff in the three governance structures

When the farmers process individually and trade in the market directly, the product quality is merely decided by their subjective risk toward the market uncertainty. However, when the farmers' subjective risks toward the market and production uncertainty are so large to produce a negative certainty equivalent payoff, they will not participate in the market. By contrast, when the farmers trade with a (enterprise) processor, the risk of market uncertainty is shifted from the farmers to the processor through the contract. This result is supported by empirical findings (Knoeber and Thurman, 1995), and it may justify the trend that, fewer and fewer products are traded on open markets and production contracts are more and more common (Bogetoft and Olesen, 2004). However, the farmers still face the risk of production uncertainty. The product quality will thus be determined by the contract offered by the processor, which balances the production risk bearing and incentive provision.

The cooperative processor has the advantage over self-processing, since the risk-averse farmers can always earn a positive certainty equivalent payoff as members of the cooperative in an uncertain market. This provides a justification for the formation of agricultural cooperatives. However, the complete pooling policy is problematic. Although the complete pooling policy can bring the benefits of risk sharing that supports the quality provision of the cooperative, it goes at the detriment of its members' incentive in quality improvement. With the complete pooling policy, when a new member joins the cooperative, the loss from the free-riding dominates the benefit of risk sharing. In addition, the cooperative is not able to provide sufficient incentives for the provision of product quality. As a consequence, the cooperative's product quality will continuously decrease as its membership size increases.

Instead of using the quality incentive based on pooled quality, the IOF processor offers the farmers quality incentive based on individual product quality. Without pooling, the individualized incentive will expose the farmers more to the production uncertainty. However, the IOF processor can design an optimal contract which reaches a trade-off between providing incentives and minimizing the cost of risk. Therefore, the IOF processor is able elicit farmers to deliver products with higher quality. We can formulate the first proposition as follows: 
Proposition 1: The product quality of the cooperative with a complete pooling policy is always lower than that of the IOF.

Figure 1 provides a graphical illustration that compares the product quality of the IOF and the cooperative.

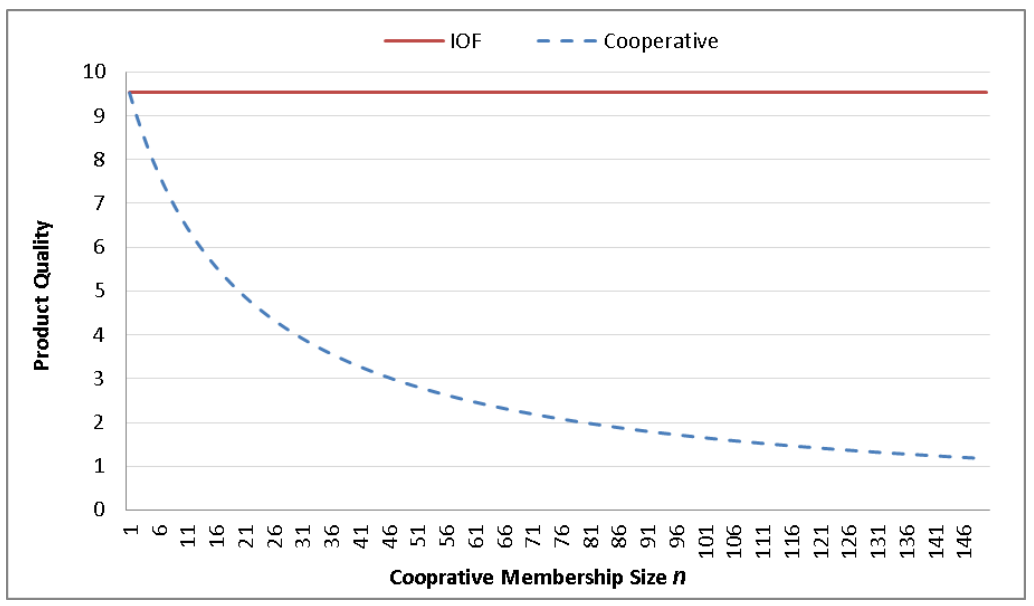

Figure 1: Product quality

How will the farmers choose the processor? As discussed previously, if self-processing and trading directly in the market brings no positive certainty equivalent payoff to the farmers due to the large uncertainties, i.e. $\frac{b^{2}}{2}\left(\frac{1}{c+k_{1}}-k_{2}\right)+C E\left(\epsilon_{1} \epsilon_{2}\right) \leq 0$, no farmers will participate in the market alone. They either form a cooperative or trade with the IOF. Assuming that both a cooperative and an IOF exist, they are attracting the supplies from the farmers in the same region. Figure 2 illustrates the competition between the cooperative and the IOF over raw produce supply. When the cooperative's membership size is $M$, each member's certainty equivalent payoff is equal to 1 . The IOF processor designs the contract subject to the farmers' participation constraint, which will be equal to 1 . The cooperative's membership size will no longer grow because the each member' certainty equivalent payoff will decrease to below 1 if more farmers join in the cooperative, and as a consequence, some members will leave and turn to the IOF. However, if the IOF processor wants to attract more suppliers, it can simply modify the contract offered to the suppliers by increasing the base payment $\alpha_{f}$. As such, the certainty equivalent payoff of the farmers who supply the IOF will be higher than the cooperative members' certainty equivalent payoff. For example, if the certainty equivalent payoff of the farmers who supply the IOF is increased from 1 to 1.5 , some cooperative members will then leave the cooperative and trade with the IOF. The cooperative membership size will decrease. With fewer members, the cooperative's product quality and members' certainty equivalent payoff will increase because the free-riding problem is relatively eased. When the membership size decreases to $M^{\prime}$, cooperative members' certainty equivalent payoff is again equal to the certainty equivalent payoff received by the farmers trading with the IOF, the members will stay in the cooperative. The membership size of the cooperative is determined by the certainty equivalent payoff that the IOF offers to its suppliers. Generally, the cooperative with a complete pooling policy is in a disadvantageous position in the competition with the IOF. The IOF can not only elicit supply with better quality, but also attract the supplies from the cooperative's members by increasing payment. The total certainty equivalent payoff (sum of farmer and processor) of each unit 
of product generated by the IOF is larger than that by the cooperative, i.e. $\frac{b^{2}}{2 c\left(1+c k_{2}\right)}>\frac{b^{2}}{2 c\left(1+n c k_{2}\right)}$. The IOF is thus more efficient than the cooperative.

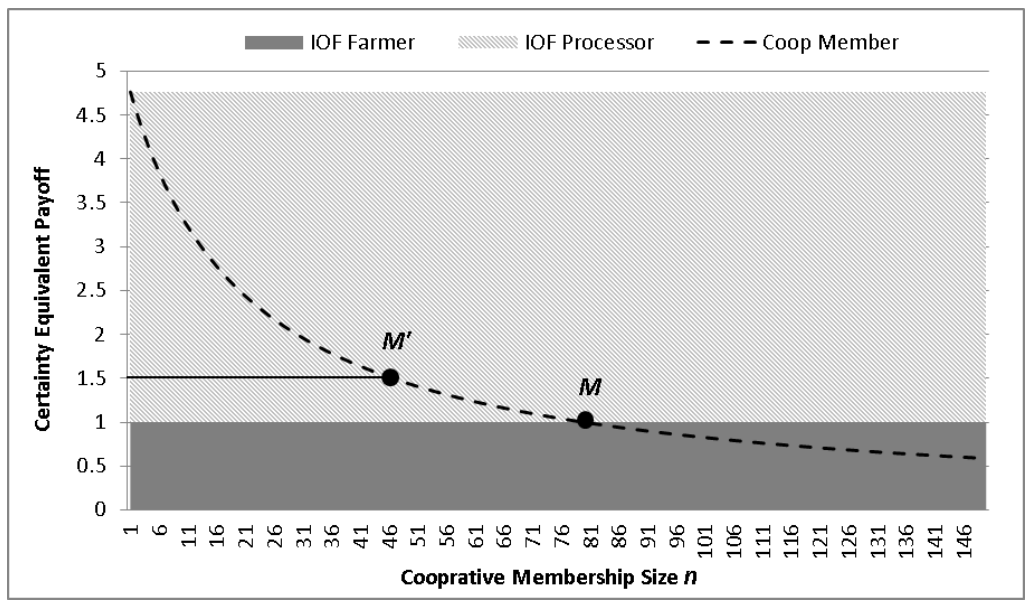

Figure 2: Certainty equivalent payoff

Another situation we have to consider is when self-processing and trading directly in the market also can bring a positive certainty equivalent payoff to the farmers, i.e. $\frac{b^{2}}{2}\left(\frac{1}{c+k_{1}}-k_{2}\right)+C E\left(\epsilon_{1} \epsilon_{2}\right)>0$. The curve in Figure 3 approximates the situations where the certainty equivalent payoff of selfprocessing is equal to zero. The shaded area below the curve thus represents the range of $k_{1}$ and $k_{2}$, within which the self-processing farmers can obtain a certain level of positive certainty equivalent payoff. This positive certainty equivalent payoff also serves as the reservation payoff of all farmers. According to Figure 2, the certainty equivalent payoff of the cooperative members will continuously decrease when the membership size increases. When the certainty equivalent payoff of the cooperative members is equivalent to the certainty equivalent payoff of the self-processing farmers, the farmers are indifferent between self-processing and becoming members of the cooperative. The cooperative's membership size will thus no longer grow. The membership size of the cooperative is determined by the certainty equivalent payoff of the self-processing. When $k_{1}$ and $k_{2}$ increase, the certainty equivalent payoff of the self-processing will decrease, so will reservation payoff of all farmers. The membership size of the cooperative will also increase. If there exists also an IOF in the region, the IOF will design the contract subject to the reservation payoff as well and takes it as the farmers' participation constraint. As such, the farmers will be indifferent in self-processing or supplying to the cooperative or the IOF. Given that $k_{1}>0, k_{2}>0$ and $C E\left(\epsilon_{1} \epsilon_{2}\right)<0$, through simple derivation we can obtain the result that the total certainty equivalent payoff of each unit of product generated by the IOF is larger than that by self-processing, i.e. $\frac{b^{2}}{2 c\left(1+c k_{2}\right)}>\frac{b^{2}}{2}\left(\frac{1}{c+k_{1}}-k_{2}\right)+$ $C E\left(\epsilon_{1} \epsilon_{2}\right)$. The IOF is also more efficient than self-processing.

We can compare the product quality of different processors according to the value of $k_{1}$ and $k_{2}$. First, the IOF's product quality is always higher than that of the cooperative (Proposition 1). Second, when the certainty equivalent payoff of self-processing is positive and $k_{2}<\frac{k_{1}}{c^{2}}$, the IOF's product quality is higher than that of the self-processing products, i.e. $\frac{b}{c\left(1+c k_{2}\right)}>\frac{b}{c+k_{1}}$. Third, when the certainty equivalent payoff of self-processing is positive 
and $k_{2}<\frac{k_{1}}{n c^{2}}$, the cooperative's product quality is higher than that of the self-processing product, $\frac{b}{c\left(1+n c k_{2}\right)}>\frac{b}{c+k_{1}}$. Finally, when self-processing and trading directly in the market brings no positive certainty equivalent payoff to the farmers ( $k_{1}$ and $k_{2}$ are in the area above the curve), there will be no self-processing. Denote the product quality of self-processing, cooperative and IOF as $Q_{m}, Q_{c}$ and $Q_{f}$, respectively. According to the values of $k_{1}$ and $k_{2}$, the rank of product quality of three different governance structures is illustrated Figure 3.

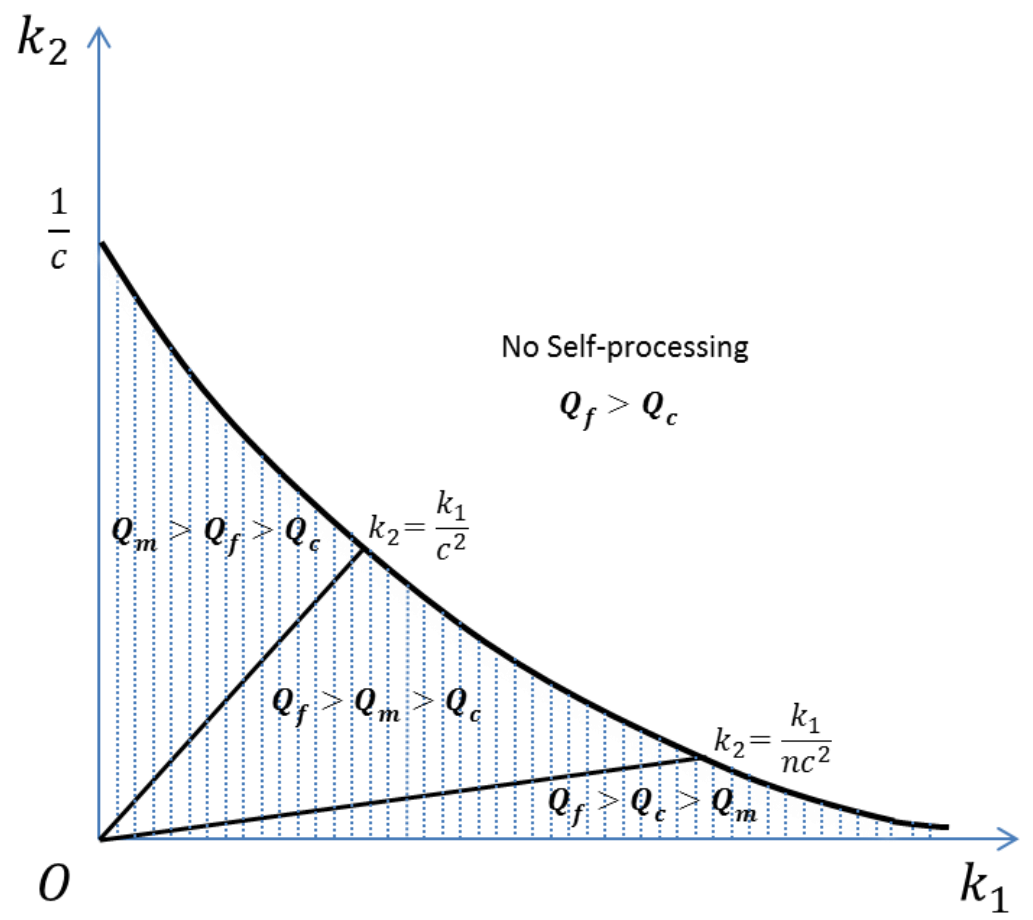

Figure 3: Uncertainties, governance structures and product quality

\section{Partial Pooling}

In this section, we investigate how a cooperative can design an optimal income rights structure by adjusting its pooling policy, in order to achieve a high product quality when the membership size is large. We extend the model of the cooperative processor of Section 2 by the decision regarding a pooling ratio $\Delta(0 \leq \Delta \leq 1)$, in addition to the decisions of the fixed payment $\alpha_{c}(\geq 0)$ and quality incentive $\beta_{c}\left(0 \leq \beta_{c} \leq b\right)$. The payment that a member will receive is modified to:

$$
P_{i}=\alpha_{c}+\beta_{c} \Delta Q_{c}+\beta_{c}(1-\Delta) q_{i}
$$

The pooling ratio $\Delta$ measures to what extent the quality incentive will be paid according to the pooled quality $Q_{c}$, whereas $1-\Delta$ denotes the portion of a member's production that receives a quality-specific price (Saitone and Sexton, 2009). Member $i$ 's economic payoff is:

$$
\pi_{i}=\alpha_{c}+\beta_{c} \Delta Q_{c}+\beta_{c}(1-\Delta) q_{i}-\frac{1}{2} c q_{i}^{2}
$$

The member' utility function is: 


$$
U_{i}=-\exp \left\{-r\left[\alpha_{c}+\frac{\beta_{c} \Delta}{n} \sum_{i}^{n}\left(q_{i}+\epsilon_{2 i}\right)+\beta_{c}(1-\Delta)\left(q_{i}+\epsilon_{2 i}\right)-\frac{1}{2} c q_{i}^{2}\right]\right\} .
$$

The member' certainty equivalent payoff is:

$$
C E_{i}=\alpha_{c}+\frac{\beta_{c} \Delta}{n} \sum_{i}^{n} q_{i}+\beta_{c}(1-\Delta) q_{i}-\frac{1}{2} c q_{i}^{2}-\frac{1}{2} k_{2} \beta_{c}^{2}\left(\frac{\Delta^{2}}{n}+(1-\Delta)^{2}\right) .
$$

The member's decision on quality is obtained by:

$$
\begin{gathered}
\frac{\partial C E_{i}}{\partial q_{i}}=\frac{\beta_{c} \Delta}{n}+\beta_{c}(1-\Delta)-c q_{i}=0 . \\
q_{i}^{*}=\frac{\beta_{c} \Delta}{n c}+\frac{\beta_{c}(1-\Delta)}{c}=\frac{\beta_{c}}{c}\left(\frac{\Delta}{n}+1-\Delta\right)
\end{gathered}
$$

The cooperative's aggregate quality is then:

$$
Q_{c}^{*}=\frac{\beta_{c}}{c}\left(\frac{\Delta}{n}+1-\Delta\right)+\frac{1}{n} \sum_{i}^{n} \epsilon_{2 i}
$$

Similarly, the cooperative processor retains no earnings and maximizes the joint certainty equivalent payoff of the processor and members, which is:

$$
\begin{aligned}
\pi_{c}=E\left[n b Q_{c}^{*}\right. & \left.-\frac{n}{2} c q_{i}^{* 2}-\frac{n}{2} k_{2} \beta_{c}^{2}\left(\frac{\Delta^{2}}{n}+(1-\Delta)^{2}\right)\right] \\
& =n\left(\frac{b \beta_{c}}{c}\left(\frac{\Delta}{n}+1-\Delta\right)-\frac{\beta_{c}^{2}}{2 c}\left(\frac{\Delta}{n}+1-\Delta\right)^{2}-\frac{1}{2} k_{2} \beta_{c}^{2}\left(\frac{\Delta^{2}}{n}+(1-\Delta)^{2}\right)\right) .
\end{aligned}
$$

The cooperative maximizes the $\pi_{c}$ by choosing $\beta_{c}\left(0 \leq \beta_{c} \leq b\right)$ and $\Delta(0 \leq \Delta \leq 1)$ :

$$
\begin{gathered}
\frac{\partial \pi_{c}}{\partial \Delta}=n\left(\frac{b \beta_{c}}{c}\left(\frac{1}{n}-1\right)\right)-\frac{n \beta_{c}^{2}}{c}\left(\frac{\Delta}{n}+1-\Delta\right)\left(\frac{1}{n}-1\right)-n k_{2} \beta_{c}^{2}\left(\frac{\Delta}{n}-(1-\Delta)\right)=0 . \\
\Delta^{*}=\frac{\left(\frac{b}{c}-\frac{\beta_{c}}{c}\right)\left(\frac{1}{n}-1\right)+k_{2} \beta_{c}}{\frac{\beta_{c}}{c}\left(\frac{1}{n}-1\right)^{2}+k_{2} \beta_{c}\left(\frac{1}{n}+1\right)} .
\end{gathered}
$$

When $n$ is large, $\frac{1}{n} \approx 0$ :

$$
\Delta^{*} \approx \frac{c k_{2} \beta_{c}+\beta_{c}-b}{c k_{2} \beta_{c}+\beta_{c}}=1-\frac{1}{\left(1+c k_{2}\right) \frac{\beta_{c}}{b}} .
$$

Because $0 \leq \beta_{c} \leq b$, the pooling ratio the cooperative can choose is:

$$
0 \leq \Delta^{*} \leq \frac{c k_{2}}{1+c k_{2}}
$$


And:

$$
\begin{gathered}
\frac{\partial \pi_{c}}{\partial \beta_{c}}=\frac{n b}{c}\left(\frac{\Delta}{n}+1-\Delta\right)-\frac{n \beta_{c}}{c}\left(\frac{\Delta}{n}+1-\Delta\right)^{2}-n k_{2} \beta_{c}\left(\frac{\Delta^{2}}{n}+(1-\Delta)^{2}\right)=0 . \\
\beta_{c}^{*}=\frac{\frac{b}{c}\left(\frac{\Delta}{n}+1-\Delta\right)}{\frac{1}{c}\left(\frac{\Delta}{n}+1-\Delta\right)^{2}+k_{2}\left(\frac{\Delta^{2}}{n}+(1-\Delta)^{2}\right)} \approx \frac{b}{\left(1+c k_{2}\right)(1-\Delta)} . \\
\frac{\beta_{c}^{*}}{b}=\frac{1}{\left(1+c k_{2}\right)(1-\Delta)} .
\end{gathered}
$$

Because $0 \leq \Delta^{*} \leq \frac{c k_{2}}{1+c k_{2}}$ :

$$
\frac{1}{1+c k_{2}} \leq \frac{\beta_{c}^{*}}{b} \leq 1
$$

In sum, we obtain the optimal policy of the cooperative:

$$
\frac{\beta_{c}^{*}}{b}\left(1-\Delta^{*}\right)=\frac{1}{\left(1+c k_{2}\right)}
$$

Denote $\gamma^{*}=\frac{\beta_{c}^{*}}{b},(0 \leq \gamma \leq 1)$, as the ratio between the quality incentive of the cooperative and the marginal market price with respect to the product quality in the market. It measures the relative strength of the cooperative's quality incentive. In sum, the optimal income rights structure $S^{*}$ of the cooperative can be written as:

$$
S^{*}=\gamma^{*}\left(1-\Delta^{*}\right)=\frac{1}{1+c k_{2}}, \quad \frac{1}{1+c k_{2}} \leq \gamma^{*} \leq 1 \text { and } 0 \leq \Delta^{*} \leq \frac{c k_{2}}{1+c k_{2}} .
$$

With the optimal income rights structure, the expected aggregate quality of the cooperative is:

$$
Q_{c}=E\left[\frac{\beta_{c}^{*} \Delta^{*}}{n c}+\frac{\beta_{c}^{*}\left(1-\Delta^{*}\right)}{c}+\frac{1}{n} \sum_{i}^{n} \epsilon_{2 i}\right] \approx \frac{b}{c\left(1+c k_{2}\right)} .
$$

Because the cooperative operates with a zero-profit constraint, the base price can be obtained by:

$$
\begin{gathered}
b Q_{c}^{*}-\left[\alpha+\beta_{c}^{*} \Delta^{*} Q_{c}^{*}+\beta_{c}^{*}\left(1-\Delta^{*}\right) q_{i}^{*}\right]=0 . \\
\alpha_{c}^{*}=q_{i}^{*}\left(b-\beta_{c}^{*}\right) .
\end{gathered}
$$

Figure 4 illustrates the optimal income rights structures the cooperative can choose. Given a certain level of members' subjective risk toward the production uncertainty $k_{2}$ and quality provision cost coefficient $c$, the solid part of the curve represents the efficient frontier of the optimal income rights structure. 


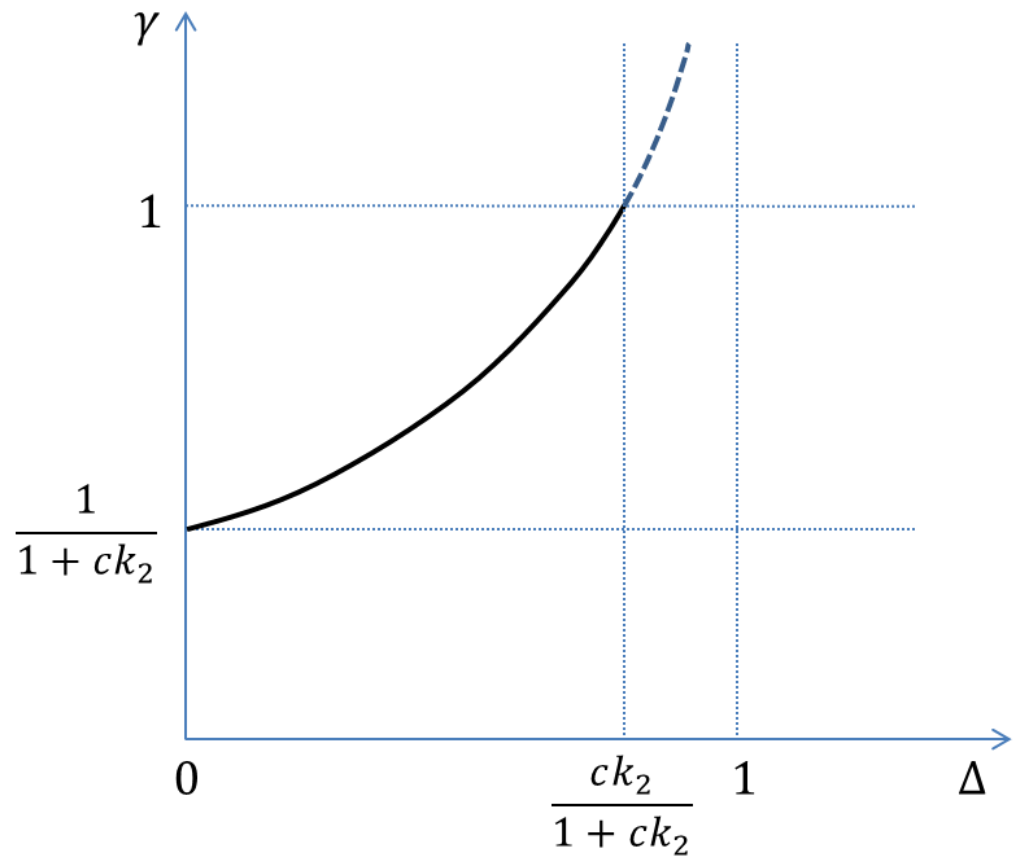

Figure 4: The Optimal income rights structure of cooperatives

Several important implications regarding the optimal income rights structure can be drawn. First, a high pooling ratio is associated with a high relative quality incentive strength $\gamma$. While the high pooling ratio reduces the disutility of the risk premium term $\frac{1}{2} k_{2} \beta_{c}^{2} \frac{\Delta^{2}}{n}$ in the members' certainty equivalent payoff, it also reduces the members' incentive to improve product quality and boosts free-riding. Hence, a high quality incentive is needed to maintain the product quality provision from the members when the pooling ratio is high. On the other hand, when the pooling ratio is low, the relative quality incentive strength $\gamma$ must decrease as well. When the pooling ratio is low, its risksharing function will decrease whereas the quality incentive will become effective due to less freeriding. The low pooling ratio individualizes not only the risk of production uncertainty but also the rewards of product quality. Therefore, with a low pooling ratio, the cooperative only needs a relative low incentive strength to support the product quality but a high base price to decrease the members' disutility from the risk of production uncertainty.

Second, the complete pooling policy, i.e. $\Delta=1$, should by no means be adopted by the cooperative. Instead, the highest pooling ratio that the cooperative can enact is $\Delta_{\max }=\frac{c k_{2}}{1+c k_{2}}$. When the cooperative chooses $\Delta_{\max }$, the base price $\alpha_{c}$ will be zero and the quality incentive $\beta_{c}$ will be $b$ in the corresponding optimal payment formula. It entails that the members will received no base price and the cooperative's quality incentive will be equal to the quality marginal price of the market. The relative quality incentive strength $\gamma$ is then equal to 1 . In other words, with pooling ratio $\Delta_{\max }$, the cooperative does not need to pay a base payment to members to bear their risk of production uncertainty. The pooling arrangement itself has already minimized the cost of risk by risk-sharing. If the cooperative's pooling ratio is set to be higher than $\Delta_{\max }$, the cooperative has to use a relative quality incentive strength $\gamma>1$, i.e. $\beta_{c}>b$, to maintain the product quality level. The reason is that a pooling ratio higher than $\Delta_{\max }$ further reduces the members' incentive in quality improvement. To sustain the product quality, a more powerful incentive must be provided. However, 
as the cooperative operates on a zero-profit condition, choosing $\beta_{c}>b$ entails that $\alpha_{c}<0$, i.e. the cooperative charges the members a base fee for each unit of produce they deliver. This is impractical and it also proves that the traditional principle of complete pooling, which we have modeled in Section 2, is not efficient. Therefore, there is an upper bound on the pooling ratio that the cooperative can adopt. Beyond that, the cooperative will be not able to maintain its product quality with the increase of membership size. The dashed part of the curve in Figure 3 represents the inapplicable income rights structure. Another implication of the upper bound on the pooling ratio is that $\Delta_{\max }$ will decrease when the farmers' subjective risk toward production uncertainty $k_{2}$ and quality provision cost coefficient $c$ decrease. It entails that, while agricultural modernization nowadays attenuates the production uncertainty and quality provision cost, the upper bound on the pooling ratio is continuously lowered.

Third, the cooperative can adopt the no-pooling policy i.e., $\Delta=0$, which means that the quality incentive will be fully individualized. This is the same arrangement as in the contract of the IOF. Under this circumstance, a lowest quality incentive $\beta_{c}=\frac{b}{1+c k_{2}}$ must be chosen, otherwise the members will encounter a large disutility brought by the risk premium $\frac{1}{2} k_{2} \beta_{c}^{2}$, which is also fully individualized under the no-pooling policy. As the low quality incentive $\beta_{c}$ is accompanied with a high base payment $\alpha_{c}$, when there is no pooling to share the members' risk of production uncertainty, the highest base payment is provided to the members for bearing the risk.

In sum, the optimal income rights structure $S^{*}$, which consists of the decisions of the pooling ratio and relative quality incentive strength, provides the cooperative with optimal alignments between pooling, incentive and risk bearing, thereby supporting the quality provision of the cooperative. The cooperative's decision regarding the pooling ratio is flexible as it can choose from a range of pooling ratios. However, the cooperative may prefer a specific pooling ratio, which is able to bring the organization additional benefits. We leave this topic for further research.

The second proposition is formulated as follows:

Proposition 2: The range of the efficient equilibrium pooling ratio of the cooperative is $\left[0, \frac{c k_{2}}{1+c k_{2}}\right]$.

Table 3 compares the product quality, farmers' certainty equivalent payoff and the processor's payoff per unit of product in different governance structures when the cooperative adopts the optimal income rights structure with partial pooling:

\begin{tabular}{|c|c|c|c|}
\hline & Self-processing & IOF & Cooperative \\
\hline $\begin{array}{c}\text { Product } \\
\text { Quality }\end{array}$ & $\frac{b}{c+k_{1}}$ & $\frac{b}{c\left(c k_{2}+1\right)}$ & $\frac{b}{c\left(c k_{2}+1\right)}$ \\
\hline $\begin{array}{c}\text { Farmers' CE } \\
\text { Payoff }\end{array}$ & $\frac{b^{2}}{2}\left(\frac{1}{c+k_{1}}-k_{2}\right)+C E\left(\epsilon_{1} \epsilon_{2}\right)$ & $\frac{b^{2}}{2 c\left(c k_{2}+1\right)}$ & $\frac{b^{2}}{2 c\left(c k_{2}+1\right)}$ \\
\hline $\begin{array}{c}\text { Processor's } \\
\text { payoff }\end{array}$ & n.a. & 0 & 0 \\
\hline
\end{tabular}

Table 3: Product quality and certainty payoff in the three governance structures

With the optimal income rights structure, the cooperative's product quality can reach the same level as that of the IOF. Importantly, the certainty equivalent payoff the members receive increases, so does the farmers' reservation payoff. As the IOF processor is competing with the cooperative for the 
supplies of raw produce from the farmers in the same region, it has to increase the certainty payoff of its suppliers to the level as high as the farmers' reservation payoff. Therefore, the competition pushes the IOF processor's profit to zero and makes the farmers indifferent between supplying the

cooperative and the IOF. Because $\frac{b^{2}}{2 c\left(1+c k_{2}\right)}>\frac{b^{2}}{2}\left(\frac{1}{c+k_{1}}-k_{2}\right)+C E\left(\epsilon_{1} \epsilon_{2}\right)$, i.e. the certainty equivalent payoff of the farmers trading with an enterprise processor is strictly larger than that of self-processing farmers, no farmer will choose self-processing. The governance structure of the cooperative and the IOF are both efficient, while self-processing is inefficient. Our third proposition can be formulated as follows:

Proposition 3: The product quality of the cooperative with an optimal income rights structure will be equivalent to that of the IOF.

\section{Discussion}

We have highlighted two different types of risk in our model and investigate their impacts on the quality decisions of risk-averse farmers. Specifically, our results imply that the market uncertainty and production uncertainty both will deter the provision of product quality. If the payoff regarding the product quality is uncertain, the risk-averse farmers will be reluctant to invest efforts in quality improvement. We show that an important attribute of the production or marketing contract is to shift the risk of market uncertainty from the farmers to the processor. Via the contract, the farmers' participation can be secured. Since the farmers still face the risk of production uncertainty, another function of the contract is to balance the production risk bearing and incentive, in order to elicit the optimal product quality from the farmers. The processor thus optimizes the contract according to its objective by choosing the payment formula. It is proved that the cooperative processor with a complete pooling policy is disadvantageous in the competition with the IOF processor. The latter can elicit the optimal quality provision from the farmers by offering an efficient contract with individualized quality incentives. By contrast, the product quality of the cooperative with the complete pooling policy will be lower than that of the IOF, and will decrease when the cooperative becomes large in terms of membership size. Therefore, the cooperative must change its income rights structure and adopt a partial pooling policy.

When investigating the optimal income rights structure of the cooperative, we relax its traditional principle of complete pooling and the cooperative can choose a pooling ratio. This adds an additional dimension in the cooperative's approach of aligning risk-sharing and incentive of the members. One important benefit of the pooling is to share the risk of production uncertainty among members. When the risk is shared by more members, the disutility of risk is smaller for each member and the members are more willing to invest efforts in quality improvement. However, the pooling also has a negative impact on the quality provision because it will reduce the member's incentive and cause free-riding when the members make quality decisions. Under the circumstance of pooling, the more members the cooperative has, the weaker is the incentive. Therefore, the cooperative must find the applicable pooling ratios, with which the pro and con of the pooling policy can be balanced by the linear contract $P=\alpha+\beta q$. Based on this rationale, we derive the optimal income rights structure for the cooperative, under which the cooperative can maintain a high product quality even when the membership size is growing and large. The configuration of the optimal income rights structure is flexible. In order to reach the optimal product quality, the cooperative needs not necessarily imitate the IOF by abandoning pooling and adopting a fully individualized quality incentive. Instead, the 
cooperative can choose from a range of pooling ratios. When a high pooling ratio is chosen, the risk of production uncertainty is well-shared, the cooperative can choose a contract with a stronger quality incentive. When the a low pooling ratio is chosen, the incentive as well as the risk is more individualized, the cooperative thus must choose a contract with a large base payment and a weak quality incentive, which better bears the members' production risk. As such, the cooperative has more flexibility in its payment arrangements. Importantly, we emphasize that when the members have subjective risk toward production uncertainty, the pooling ratio must be lower than an upper bound. With a pooling ratio higher than this upper bound, the pro and con of pooling can no longer be balanced by a contract, and the cooperative's product quality will therefore decrease as the cooperative grows.

Table 4 summarizes the effects of the institutional arrangements of different governance structures on the provision of product quality:

\begin{tabular}{|l|c|c|c|c|}
\hline & $\begin{array}{c}\text { Self- } \\
\text { processing }\end{array}$ & IOF & $\begin{array}{c}\text { Coop- } \\
\text { Complete Pooling }\end{array}$ & $\begin{array}{c}\text { Coop- } \\
\text { Optimal Structure }\end{array}$ \\
\hline Shifting Market Risk & No & Yes & Yes & Yes \\
\hline Pooling of Production Risk & No & No & Yes & Yes \\
\hline Free-riding & No & No & Yes & Yes \\
\hline Bearing Production Risk by $\alpha$ & No & Yes & Yes & Yes \\
\hline Providing Sufficient Quality Incentive by $\beta$ & No & Yes & No & Yes \\
\hline
\end{tabular}

Table 4: Effects on quality provision in the three governance structures

Our model also provides an explanation for the coexistence of IOFs and cooperatives in agricultural markets. We argue that by abandoning the complete pooling policy and adopting an optimal income right structure, cooperatives can overcome their disadvantageous position in the competition with IOFs. Theoretically, the product quality of the IOF and the cooperative with an optimal income rights structure can both reach the same optimal level. However, in reality, the competition between the IOF and cooperative is much more dynamic. First of all, they may have different and non-precise judgments on the farmers' absolute risk aversion, quality provision cost coefficient, and the level of production uncertainty, which can lead to their different decisions regarding the payment formula. Second, the quality incentive of the cooperative is normally projected by the members as a certain promise, because the members own and control the processor, they can decide and enforce the incentive collectively. By contrast, when trading with the IOF, the farmers may have additional subjective risk toward the IOF's quality measurement and payment (Balbach, 1998; Gow et al., 2000). This may distort the farmers' decisions in product quality. Third, the cooperative processor may be, to some extent, risk averse instead of risk neutral. They may thus adopt a more conservative policy regarding the quality provision. All these factors may play a role in the quality competition between cooperatives and IOFs. In addition, different processors are also competing in the quality dimension by other means. For example, they may provide the farmers with farming supplies and technical supports in order to decrease the farmers' subjective risk toward production uncertainty $k_{2}$, or help the farmers to decrease the quality provision cost coefficient $c$. With such measures, they are able to further increase the product quality.

\section{Conclusion and further research}

Normally an uncertain payoff is considered less valuable than the certain payoff with the same expected value. Confronted with the risk of market and product uncertainty, the risk-averse farmers' 
efforts of product quality provision will be deterred, especially, when they trade directly in the market individually. By forming a cooperative, the risk-averse farmers can obtain benefits given that the cooperative processor insures them from the risk of market uncertainty. Pooling also reduces the risk of product uncertainty. However, with a complete pooling policy, the members are rewarded for their product quality according to the pooled quality of the cooperative. The farmers can also trade with the IOF, which rewards the farmers' product quality on an individualized base. In a principal-agent framework with the processor as risk-neutral principal and farmers as risk-averse agents, we compare the quality provision of a cooperative and an IOF. It is shown that the traditional principle of complete pooling policy places the cooperative at a disadvantage relative to the IOF in a quality-differentiated market. The reason is that, with the complete pooling policy, when a new member joins the cooperative, the loss from the free-riding dominates the benefit of risk sharing. As a consequence, the cooperative's product quality will continuously decrease as its membership size increases. By contrast, the IOF processor can design an optimal contract that reaches a trade-off between providing incentives and minimizing the cost of risk. Therefore, the IOF processor elicits higher quality from farmers.

However, cooperatives can overcome this disadvantage by relaxing the traditional principle of complete pooling to partial pooling. We find that given the members' subjective risk toward product uncertainty $k_{2}$, the complete pooling policy should be by no means adopted by cooperatives. Instead, there is an upper bound on the pooling ratio that the cooperative can adopt. We prove that by designing an optimal income rights structure for the organization, cooperatives can maintain an optimal product quality level, which is equivalent to the product quality level of the IOF. The configuration of the optimal income rights structure is flexible. Cooperatives can choose from a range of pooling ratios, from no pooling to the upper bound pooling ratio. When a high pooling ratio is chosen, the risk of production is well-shared, the cooperative can choose a contract with a stronger quality incentive $\beta$. When a low pooling ratio is chosen, the incentive as well as the risk is more individualized, the cooperative thus must choose a contract with a large base payment $\alpha$, which bears the members' production risk, and a weak quality incentive $\beta$. As such, the cooperative also has more feasibility in payment arrangements. However, why cooperatives may choose a specific pooling ratio within the range needs to be further investigated.

In general, our model contributes to comparing the product quality provision of cooperatives and IOFs by capturing the uncertainties in agribusiness and the farmers' characteristic of risk aversion. We argue that cooperatives are able to compete with IOFs in a quality-differentiated market if an optimal income rights structure is adopted. This may provide an explanation for the coexistence of cooperatives and IOFs in many agricultural sectors.

There are various possibilities for further research by relaxing some assumptions of our model. One assumption is that the farmers are identical, with respect to both the absolute risk aversion level and quality provision efficiency. Hence, the adverse selection effect of heterogeneous farmers is not addressed in our model. Second, we don't distinguish the common and idiosyncratic production uncertainty, and just model the contract based on the absolute quality evaluation. However, the contract rewarding farmers based on the relative product quality is also commonly used in agricultural production, which shifts the common part of the production uncertainty to the processor. Third, as mentioned in Section 3, the cooperative processor may be risk-averse as well. However, the level of absolute risk aversion of the cooperative as a whole may be less than that of 
each individual member. In addition, the IOF may behave opportunistically ex-post regarding quality measurement and payment. This entails an additional risk for the farmers who trade with the IOF. Lastly, the final product market is assumed to be perfectly competitive in our model. However, in many agricultural sectors, the markets are oligopolistic. Different market settings may change the behaviors of the processors regarding contract optimization. In sum, we argue that there are several additional factors which may potentially influence the quality provision of cooperatives and the competition with IOFs. 


\section{Reference}

Balbach, J.K., (1998), "The Effect of Ownership on Contract Structure, Costs, and Quality: The Case of the U.S. Beet Sugar Industry", in Royer, J.S. and R.T. Rogers, the Industrialization of Agriculture: Vertical Coordination in the U.S. Food System, Aldershot, 1998, pp. 155-184.

Bogetoft, P., and Olesen, H. B. (2004), "Design of Production Contract: Lessons from Theory and Agriculture", Copenhagen Business School Press.

Bolton, P., and Dewatripont, M. (2005), “Contract Theory”, MIT Press, Cambridge, MA.

Cechin, A., Bijman, J., Pascucci, S., Zylbersztajn, D., and Omta, O. (2012), "Quality Provision in Cooperative versus Investor Owned Firms: The Case of Broiler Production in Brazil", forthcoming in Managerial and Decision Economics.

Cook, M. L., (1995), "The Future of U.S. Agricultural Cooperatives: A Neo-Institutional Approach", American Journal of Agricultural Economics, 77: pp. 1153-1159.

Feng, L., Nilsson, J., Ollila, P., and Karantininis, K, (2011). “The Human Values behind Farmers' Loyalty to Their Cooperatives", Paper presented at the 5th international conference on Economics and Management of Networks, December $1-3,2011$, in Limassol, Cyprus.

Fulton, M., (1995), "The Future of Canadian Agricultural Cooperatives: A Property Rights Approach". American Journal of Agricultural Economics, 77(5): pp. 1144-1152.

Hendrikse, G.W.J., (2011), "Pooling, Access, and Countervailing Power in Channel Governance”, Management Science, 57(9): pp. 1692-1702.

Holmström, B., (1979), “Moral Hazard and Observability”, The Bell Journal of Economics, 10(1).

Knoeber, C.R., and Thurman, W.N. (1995), “'Don't Count Your Chickens...": Risk and Risk Shifting in the Broiler Industry', American Journal of Agricultural Economics, 77(3): pp. 486-496.

Mérel, P.R.; Saitone, T.L. and Sexton, R.J., (2009), “Cooperatives And Quality-Differentiated Markets: Strengths, Weaknesses And Modelling Approaches", Journal of Rural Cooperation, 37(2): pp. 201-224.

Mussa, M., and S. Rosen, (1978), "Monopoly and Product Quality", Journal of Economic Theory, 18: pp. 301317.

Staatz, J.M. (1987), "The Structural Characteristics of Farmer Cooperatives and Their Behavioral Consequences", ACS Service Report No. 18. U. S. Department of Agriculture.

Saitone, T.L. and Sexton, R.J., (2009), "Optimal Cooperative Pooling in a Quality-Differentiated Market", American Journal of Agricultural Economics, 91(5): pp. 1224-1232.

Uzea, F.U., and Fulton, M.E. (2009), "The Use of Identity in Strategic Network", Proceedings of the International Association for Research in Economic Psychology and Society for the Advancement of Behavioural Economics Joint Conference, Halifax, Nova Scotia, July 7-11, 2009.

Vitaliano, P. (1983), “Cooperative Enterprise: An Alternative Conceptual Basis for Analyzing a Complex Institution", American Journal of Agricultural Economics, 65: pp. 1078-1083. 